\title{
Vulnerabilidade socioambiental no Oeste Metropolitano do Rio de Janeiro: estratégias de prevenção a riscos
}

Socioenvironmental vulnerability in the Metropolitan West of Rio de Janeiro: risk prevention strategies

Vulnerabilidad socioambiental en el Oeste Metropolitano de Río de Janeiro: estrategias de prevención de riesgos

Vulnérabilité socio-environnementale dans l'Ouest Métropolitain de Rio de Janeiro: stratégies de prévention des risques

Heitor Soares de Farias, Karine Bueno Vargas, Tiago Badre Marino, Gustavo Mota de Sousa e Andrews José de Lucena

\section{(2) OpenEdition}

\section{Journals}

Edição electrónica

URL: http://journals.openedition.org/espacoeconomia/14182

DOI: 10.4000/espacoeconomia.14182

ISSN: 2317-7837

\section{Editora}

Núcleo de Pesquisa Espaço \& Economia

\section{Refêrencia eletrónica}

Heitor Soares de Farias, Karine Bueno Vargas, Tiago Badre Marino, Gustavo Mota de Sousa e Andrews José de Lucena, « Vulnerabilidade socioambiental no Oeste Metropolitano do Rio de Janeiro: estratégias de prevenção a riscos », Espaço e Economia [Online], 19 | 2020, posto online no dia 17 agosto 2020, consultado o 09 setembro 2020. URL : http://journals.openedition.org/ espacoeconomia/14182 ; DOI : https://doi.org/10.4000/espacoeconomia.14182 


\title{
Vulnerabilidade socioambiental no Oeste Metropolitano do Rio de Janeiro: estratégias de prevenção a riscos
}

\author{
Socioenvironmental vulnerability in the Metropolitan West of Rio de Janeiro: risk \\ prevention strategies \\ Vulnerabilidad socioambiental en el Oeste Metropolitano de Río de Janeiro: \\ estrategias de prevención de riesgos \\ Vulnérabilité socio-environnementale dans l'Ouest Métropolitain de Rio de \\ Janeiro: stratégies de prévention des risques
}

Heitor Soares de Farias, Karine Bueno Vargas, Tiago Badre Marino, Gustavo Mota de Sousa e Andrews José de Lucena

\section{Introdução}

1 Após a transferência da capital federal para Brasília, nos anos 1960, o Rio de Janeiro passou a sofrer perdas políticas e econômicas, estancadas com a criação do Estado da Guanabara. No entanto, no seu entorno estava o empobrecido Estado do Rio de Janeiro, tendo Niterói como capital. Com o discurso de favorecimento ao desenvolvimento da região, em 1975, houve a fusão desses dois Estados - da Guanabara e do Rio de Janeiro dando origem ao novo Estado do Rio de Janeiro, tendo a cidade do Rio de Janeiro como capital. A fusão de dois Estados muito diferentes economicamente agravou a crise que já atingia a economia fluminense (SANTOS, 2003).

2 Um dos principais motivos para o agravamento da crise foi a não realização do projeto para superar os problemas de integração do novo Estado do Rio de Janeiro, pensado ainda nos anos de 1970. Essa integração se daria a partir da criação de uma via alternativa que comportasse o fluxo de veículos de grande porte, passando por fora da 
capital, circulando pela Baixada Fluminense. Assim, criaria nessa área uma nova frente de desenvolvimento, desconcentrando os investimentos em infraestrutura e a oferta de emprego e renda. Essa obra só saiu do papel em 2014, com a construção da rodovia BR-493, mais conhecida como Arco Metropolitano.

Para Oliveira e Oliveira (2020, p. 43) "no decorrer dos primeiros anos deste século, um novo cenário econômico mundial e a ascensão de um novo projeto político e de desenvolvimento no Brasil, influíram na instituição de mudanças econômicas e sociais no espaço metropolitano do Rio de Janeiro". Essa conjunção de fatores, entre eles o alinhamento político entre governos federal e estadual, o que não acontecia há muitas décadas, permitiu que o Arco Metropolitano se transformasse em realidade.

Junto com ele, uma série de grandes projetos, investimentos públicos e privados, com a perspectiva de reestruturação produtiva e a retomada da economia em curto espaço de tempo, que incluíram a construção do Complexo Petroquímico do Rio de Janeiro (COMPERJ), no município de Itaboraí, no leste metropolitano; construção da siderúrgica TKCSA (antiga Thyssenkrüpp Companhia Siderúrgica do Atlântico e atual Ternium Brasil) no distrito industrial de Santa Cruz, na Zona Oeste do município do Rio de Janeiro; articulados pela recém-criada rodovia BR-493 ao Porto de Itaguaí, também ampliado, fundamental para o comércio exterior brasileiro pela movimentação de minério de ferro e carvão siderúrgico e pelo embarque e desembarque de contêineres e veículos leves de carga (GUSMÃo, 2010).

5 Hoje, a rodovia BR-493 contorna a metrópole, passando por sua periferia, densamente povoada, que reúne cerca de $30 \%$ da população da região metropolitana, que sofre com diversos tipos de carência social e de infraestrutura, e é para onde se destinam os empreendimentos com grande potencial poluidor citados. O Oeste Metropolitano, pela presença do Porto e da companhia siderúrgica Ternium Brasil, tem sido o principal eixo de expansão metropolitana. Entre 1990 e 2010, esta foi a principal área de incorporação de novas terras ao tecido metropolitano, apresentando taxas de crescimento populacional mais aceleradas atualmente no estado do Rio de Janeiro (GUSMÃO, 2010).

6 Já a borda leste da região metropolitana, onde foi pensada a localização do COMPERJ, encontra-se menos dinâmica economicamente. Planejado para ser o maior pólo petroquímico da América do Sul, com potencial para atrair mais de 700 empresas para atuarem na indústria de transformação, o COMPERJ acabou não sendo construído devido à crise do setor petrolífero (FARIAS, 2020).

7 Cabe lembrar que toda essa transformação está ocorrendo na Região Metropolitana do Rio de Janeiro (RMRJ), um sistema social-ambiental altamente complexo em virtude da sua morfologia, ocupação urbana, circulação atmosférica, unidades de conservação e outras categorias florestais encravadas no meio urbano. É um espaço favorável à manifestação de diversas anomalias oriundas dos seguintes fatores: disfunção ambiental urbana, como as ilhas de calor, resultado do impacto térmico acentuado da superfície urbana e a sua condução a situações de stress térmico; perda da biodiversidade, resultado das ocupações legais e ilegais do solo (urbano) e sua transformação em ambiente alterado ou construído; e, finalmente, concentração de poluentes atmosféricos, resultado da ampliação de fontes fixas e móveis (unidades industriais e veículos).

8 Desta maneira, acompanhando a expansão metropolitana e as transformações que vêm sendo promovidas no Oeste Metropolitano, um grupo de pesquisadores reuniu esforços para constituir o Laboratório Integrado de Geografia Física Aplicada (LIGA). 0 objetivo é 
estudar os riscos produzidos a partir da interação desse vetor de desenvolvimento econômico com uma população de grande vulnerabilidade social, e, neste contexto da climatologia, geoecologia da paisagem e biogeografia urbana, apresentando um diagnóstico e estratégias preventivas aos riscos potenciais do uso e ocupação territorial, colaborando com o planejamento e desenvolvimento sustentável da região.

\section{O Oeste Metropolitano}

Por sua posição geográfica e por conta dos processos históricos, econômicos, jurídicos e políticos, a RMRJ é hoje o segundo polo de concentração demográfica e de atividades econômicas do país, contendo um grande volume de atividades e fluxos, oferta de bens e serviços mais especializados e uma alta taxa de urbanização. A RMRJ concentra cerca de $75 \%$ da população estadual e é sobrecarregada regionalmente pela concentração de grande parte dos serviços, reduzindo a força política e econômica do interior fluminense (MARAFON et al., 2011).

O Oeste Metropolitano apresenta características físicas e ambientais relativamente semelhantes e pode ser considerado uma subárea da RMRJ. É uma região situada em uma ampla e importante área de baixada, permeada por cursos d'água que dissecam seu relevo, os seus maciços costeiros, e que contempla baixos índices de desenvolvimento humano, como educação e renda. A região foi definida pelos bairros da Zona Oeste da cidade do Rio de Janeiro, a Área de Planejamento 5 (Bangu, Gericinó, Padre Miguel, Senador Camará, Campos dos Afonsos, Deodoro, Jardim Sulacap, Magalhães Bastos, Realengo, Vila Militar, Campo Grande, Cosmos, Inhoaíba, Santíssimo, Senador Vasconcelos, Barra de Guaratiba, Guaratiba, Pedra de Guaratiba, Paciência, Santa Cruz e Sepetiba), e pelos municípios de uma porção da Baixada Fluminense, sendo: Itaguaí, Seropédica, Paracambi, Japeri, Queimados e Nova Iguaçu, conforme representado na Figura 1. 
Figura 1 - Localização do Oeste Metropolitano na Região Metropolitana do Rio de Janeiro

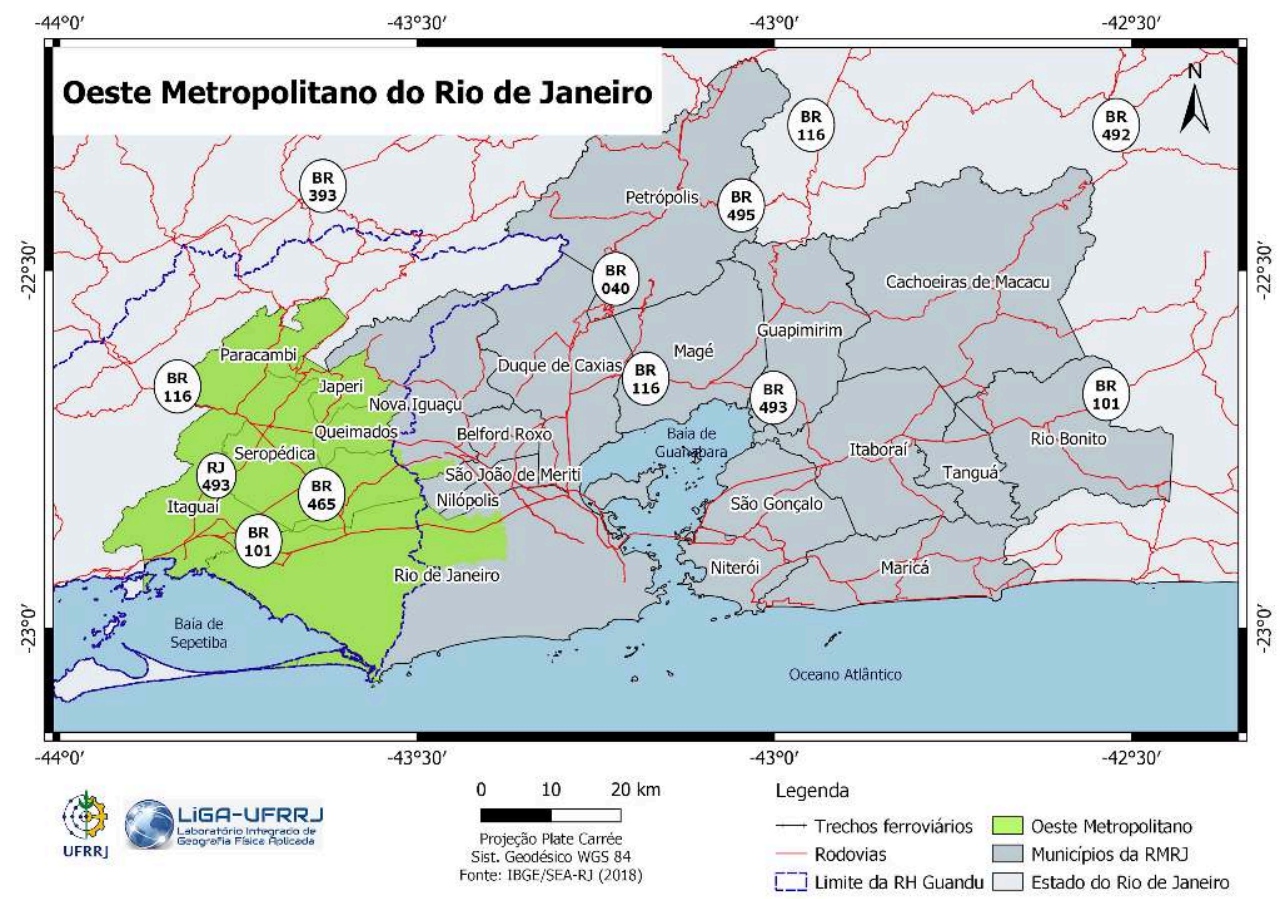

Fonte: LIGA/UFRRJ Elaborado por Gustavo Mota de Sousa condições para atrair novos investimentos para o estado do Rio de Janeiro, principalmente por ser o principal centro produtor e distribuidor de bens e serviços de todo o Estado (CEPERJ, 2020). A Zona Oeste é a área que mais se expande no município, seja no número de domicílios urbanos, seja como sede de novos grupos empresariais e serviços prestados. metropolitana, onde estão localizadas indústrias de produção petroquímica, química e plástica (Duque de Caxias, Belford Roxo e São João de Meriti); de vestuário (Nova Iguaçu e São João de Meriti) e papel/editorial/gráfica (Duque de Caxias e São João de Meriti). No entanto, também apresenta uma expressiva parcela da população subempregada nos serviços que demandam baixa qualificação de mão de obra, e que apresentam baixa remuneração (CEPERJ, 2020).

Diante desse quadro e com a disponibilidade de verba proporcionada pelo Plano de Aceleração do Crescimento (PAC), em 2007, o Arco Metropolitano voltou a ser discutido, com o intuito de dinamizar a economia fluminense, aproveitando-se de um alinhamento político entre os gestores federal e estadual. o Arco Metropolitano é uma rodovia que circunda a região metropolitana, desde Itaboraí, no leste metropolitano, atravessando praticamente todos os municípios da Baixada Fluminense, até o Porto de Itaguaí. O objetivo inicial era proporcionar maior integração da capital com seu interior, mas agora objetiva atrair investimentos para o Estado do Rio de Janeiro, convergir as diferentes rodovias que chegam ao Rio de Janeiro conduzindo a produção para o porto. Tudo isso para estimular a geração de emprego e renda, além de tirar o fluxo de caminhões que circulavam por dentro da capital, na Avenida Brasil (BR-101), desviando para o Arco Metropolitano. 
Junto com o Arco Metropolitano estava planejada a vinda de dois grandes empreendimentos: a Companhia Siderúrgica do Atlântico (CSA), localizada em Santa Cruz (atual Ternium Brasil, conforme mencionado parágrafos atrás) e o COMPERJ, localizado em Itaboraí. Ao longo do Arco Metropolitano instalar-se-iam novas indústrias consumidoras da produção das indústrias de base situadas nas suas extremidades: aço em Itaguaí e plásticos em Itaboraí, cumprindo o importante papel de dinamizar a economia do Estado do Rio de Janeiro.

15 A então CSA começou suas atividades já no ano de 2010 e o Arco Metropolitano foi inaugurado em 2014. A viabilização de sua construção seccionou uma unidade de conservação, a FLONA Mário Xavier, que é a maior área vegetada do município de Seropédica. De acordo com Vargas et al. (2019), a FLONA abrange uma área 495 hectares, a qual se encontra constantemente ameaçada por diversos impactos ambientais que pressionam seu entorno e a própria floresta, destacando-se as queimadas ilegais, uso da área para pastoreio, roubo de madeira e o trânsito de veículos no Arco Metropolitano e na Rodovia Presidente Dutra colocando em risco a fauna ali presente, dentre outros problemas também enfrentados pela maioria das unidades de conservação da RMRJ.

16 Já o COMPERJ, planejado para ser o maior polo petroquímico da América do Sul, com potencial para atrair mais de 700 empresas para atuarem na indústria de transformação (CSA, 2005), não foi construído em sua plenitude. Isso se deve à crise do setor petrolífero que atingiu diretamente à Petrobras, responsável pelo empreendimento. Assim, a borda leste da RMRJ não teve capacidade de atrair tantos investimentos quanto a borda oeste, onde localizam-se a CSA e o Porto de Itaguaí.

17 As transformações ocorridas ao longo da história recente resultaram em alterações no sistema ambiental, atingindo os sistemas geológicos e geomorfológicos, os recursos hídricos e biogeográficos, por conta das atividades de mineração, o desmatamento e a expansão urbana. Além destes, a atmosfera (local) pode ter sofrido alterações, principalmente no que tange ao balanço de energia do solo urbano, onde o aquecimento diurno e o resfriamento noturno podem ser altamente comprometidos pelas diversas propriedades físicas da nova superfície.

\section{O conceito de Risco}

Risco pode ser entendido como a iminência para a ocorrência de um evento danoso, ou seja, que ainda não aconteceu, mas que é pressentida como algo que se transformará em um evento prejudicial para os indivíduos ou coletividade de um dado espaço" (NOVEMBER, 2002, p. 19). Está cada vez mais presente em nossa sociedade, já que "a produção social da riqueza é acompanhada sistematicamente pela produção de riscos" (BECK, 2010, p. 230). Desta maneira, a permanente expansão da ocupação humana sobre as diversas áreas do planeta cria novos espaços de riscos.

19 No entanto, como a ocupação do espaço é feita de maneira diferenciada pelos distintos grupos sociais, o resultado é a exposição também diferenciada quanto aos níveis de risco. Isso ocorre porque o risco surge da relação entre um acontecimento possível, que pode ser um fenômeno natural (Desastre) ou tecnológico (Perigo), e a sociedade e sua estrutura de classes que denotam distintas vulnerabilidades sociais. Uma população 
mais vulnerável tem menos condições de resistir aos efeitos danosos de um desastre natural, ou mesmo de um cotidiano em condições de vida insalubre.

Assim, como a distribuição da riqueza na sociedade e sua reprodução no espaço não ocorrem de forma aleatória, a distribuição da saúde e da doença também não ocorre aleatoriamente, "estando associada à posição social, que por sua vez define as condições de vida e de trabalho dos indivíduos e grupos" (CNDSS, 2008, p.54). Fatores socioeconômicos, que compõem os determinantes sociais em saúde, influenciam a ocorrência de problemas de saúde e nos fatores de risco na população (BUSS e PELLEGRINI FILHO, 2007).

21 Assim, o risco é um objeto social, que pode ser reduzido, ou até mitigado com a percepção do perigo potencial, da catástrofe possível (VEYRET, 2007). Além dos fatores socioeconômicos que influenciam na vulnerabilidade social, diante das situações de risco, é preciso considerar ainda outro fator importante, a percepção do risco. Para Veyret (2007, p. 11) "Não há risco sem uma população ou indivíduo que o perceba e que possa sofrer seus efeitos. Correm-se riscos, que são assumidos, recusados, estimados, avaliados, calculados. O risco é a tradução de uma ameaça, de um perigo para aquele que está sujeito a ele e o perceba como tal".

A sociedade deve estar ciente da possibilidade de o perigo acontecer, e ter estratégias claras para remediá-lo mas, se porventura desconhece essa possibilidade, na sua visão o risco pode não existir, ainda que esteja vivendo diante dele. Nesse caso, a sociedade se torna ainda mais vulnerável, pois, sem conhecer os perigos, não pode atuar para reduzir o risco. A falta de informação aumenta o risco de viver em áreas de intensa urbanização e de precárias infraestruturas e instalações urbanísticas, bem como serviços de saneamento básico.

\section{Situações de risco no Oeste Metropolitano}

\section{Racismo ambiental e a perda da biodiversidade}

Dados apresentados pela Secretaria de Turismo do Estado do Rio de Janeiro mostram que a Região Metropolitana do Rio de Janeiro mantém 36,27\% de seu território verde conservado, sendo que cerca de um terço desse percentual está na Baixada Fluminense. o levantamento indica que nessas áreas verdes preservadas encontram-se unidades de conservação que apresentam um forte potencial turístico (Secretaria de Turismo do Estado do Rio de Janeiro, 2018).

Essas informações fizeram com que a Secretaria de Turismo do Estado do Rio de Janeiro, em conjunto com o SEBRAE/RJ, levantasse uma nova proposta de região turística para o Estado do Rio de Janeiro, denominando a Baixada Fluminense de "Baixada Verde". A proposta inclui dez municípios: Belford Roxo, Duque de Caxias, Japeri, Magé, Mesquita, Nilópolis, Nova Iguaçu, Queimados, São João de Meriti e Seropédica. Esta iniciativa tem o objetivo de proporcionar maior visibilidade e oportunidade no cenário do turismo regional à Baixada Fluminense, em uma tentativa de mudança da realidade de uma população que há décadas sofre com a pobreza, falta de emprego, baixa renda, saneamento básico inadequado e assistência à saúde precária, reflexos de um racismo não só estrutural como também ambiental. 
Para Mathias (2017), o pioneiro a trabalhar com conceito "racismo ambiental", foi o americano Benjamim Chavis no início dos anos 80, que considerava-o como a discriminação racial nas políticas ambientais, tomando como base a discriminação racial nas tomadas de decisões ambientais, como na escolha de locais de predominância de pessoas negras e pobres para o descarte de rejeitos tóxicos e instalação de indústrias poluidoras, bem como, para o sancionamento da presença de venenos e poluentes que ameaçam a vida das comunidades de cor.

No Oeste Metropolitano, um caso típico de racismo ambiental iniciou em abril de 2011, com a implementação do Centro de Tratamento de Resíduos Santa Rosa (CTR- Rio), em Seropédica. Tal empreendimento veio para suprir a demanda do lixo doméstico da cidade do Rio de Janeiro, que era depositado em Gramacho, considerado o maior lixão da América Latina, e também em Gericinó, ambos fechados concomitantemente à criação deste aterro. De acordo com dados do Relatório de Impacto Ambiental (RIMA, 2008), o empreendimento é privado, e está projetado para atender a uma demanda média de 3.673 ton/ dia de resíduos, prevendo-se uma vida útil de 20 anos.

De acordo com Freitas (2013), o CTR-Rio recebe diariamente mais de 8 mil toneladas de resíduos sólidos da cidade do Rio de Janeiro, como também uma menor quantidade de resíduos de Seropédica e Itaguaí. A maior problemática socioambiental ocorre por sua instalação ter sido construída sobre o Aquífero Piranema, apresentando inúmeras irregularidades em seu processo licitatório, o qual deixou de levar em conta diversas variáveis técnicas. Desse modo, qualquer irregularidade desta obra, afetaria não só o lençol freático, como consequentemente as Bacias Hidrográficas do Rio Guandu e Paraíba do Sul, responsáveis pelo abastecimento de água da região.

Mesmo diante de protestos da população, colocando-se contra este empreendimento sanitário intermunicipal, o mesmo foi construído, deixando claro que a dominação das áreas periféricas é realizada pelo capital, e que a população carente não é ouvida nas tomadas de decisões. Desde a criação do aterro, os moradores de Seropédica sofrem com o odor do lixo/chorume, que pode ser mais ou menos intenso de acordo com as condições atmosféricas. Ainda há relatos de aumento na proliferação de insetos nas propriedades rurais e bairros mais próximos, sendo possível visualizar na internet inúmeras reportagens de jornais importantes sobre problemáticas ambientais desse "aterro sanitário".

A partir de indicadores sintéticos de qualidade de vida aplicados à RMRJ para os anos de 2000 e 2010, Farias (2015) observou que a condição de vida da região Oeste Metropolitana tem melhorado, mas que predominam, ainda, condições de vida medianas a ruins, ocorrendo um processo de periferização das periferias, em que as áreas mais centrais e próximas a vias de circulação mais importantes, melhoraram nos quesitos de infraestrutura e prestação de serviços, refletindo na qualidade de vida da população, enquanto as áreas mais interiorizadas ficam cada vez mais abandonadas pelo poder público, mantendo-se como ruins.

Segundo Farias (2015) a variável saneamento básico, quando comparada nos municípios da RMRJ no ano de 2000 e depois em 2010, revelam que o Oeste Metropolitano teve melhoras significativas, sobretudo no serviço de abastecimento de água encanada ligada à rede geral; porém, o serviço de esgotamento sanitário ligado à rede geral de esgoto ou pluvial encontra-se menos presente ainda nos domicílios. A falta de tratamento de esgoto, bem como o recebimento de esgotos clandestinos industriais nos canais fluviais, vem cada vez mais comprometendo a qualidade ambiental dos recursos 
hídricos e a sobrevivência da biodiversidade aquática, como é o caso da Baía de Sepetiba, que apresenta elevados índices de poluição. O Complexo Hidrográfico Guandu destaca-se entre os rios mais poluídos do Estado do Rio de Janeiro, sobretudo os canais urbanos, que afetam inclusive a dinâmica ambiental de Unidades de Conservação, como é o caso do Valão dos Bois, que escoa esgoto doméstico para o interior da Floresta Nacional Mário Xavier, em Seropédica, resultante da falta de tratamento de esgotos em um condomínio do programa "Minha Casa, Minha Vida" que foi construído a sua montante, conforme pode ser observado na figura 2.

Figura 2 - Condomínio do Programa "Minha Casa, Minha Vida" alocado à montante da Floresta Nacional Mário Xavier (ao fundo)

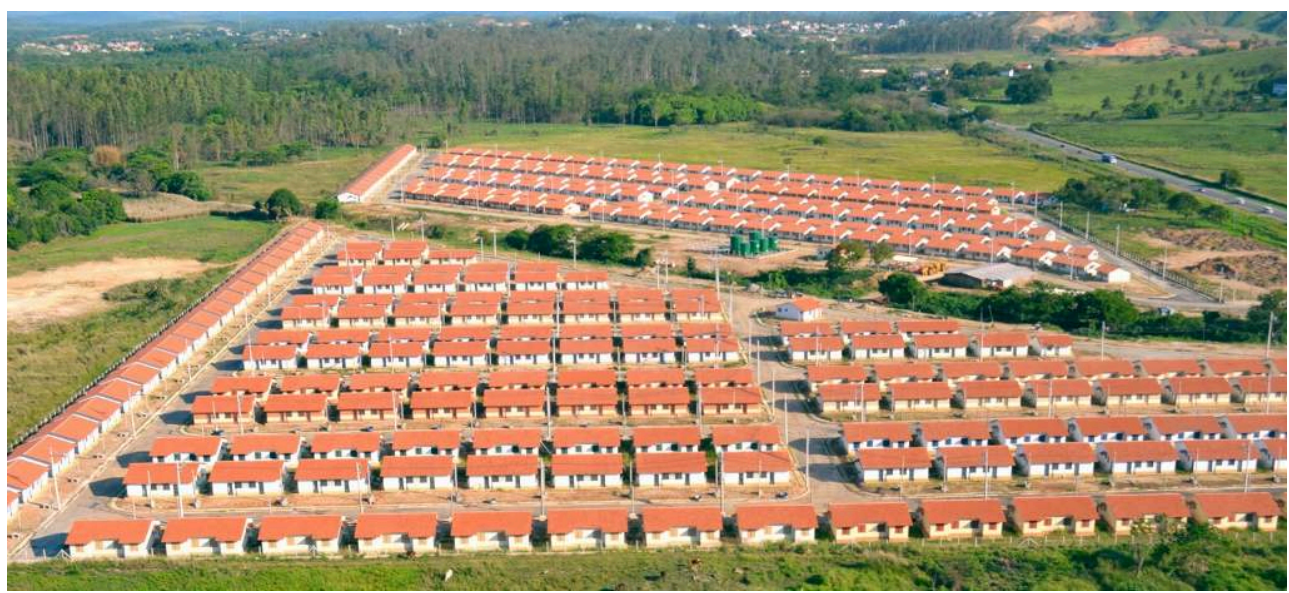

FONTE:HTTP://INDAIATUBANAOEPRAIA.COM.BR/2017/08/30/PREFEITURA-RETOMA-CADASTRAMENTOPARA-PROgRAMAS-HABITACIONAIS/

31 Além de impactos ambientais referentes à falta de saneamento básico, as unidades de conservação fragmentadas nos núcleos urbanos e periurbanos do Oeste Metropolitano sofrem diversos conflitos, como ocupações ilegais em seus territórios, com inúmeros casos de grilagem de terras, que extrapolam para suas áreas de amortecimento, como exemplo a Reserva Biológica do Tinguá. Esta unidade de conservação ocupa uma área de 24.812,90 hectares, abrangendo os municípios de Nova Iguaçu, Duque de Caxias, Miguel Pereira e Petrópolis, e, diante sua extensa área, associada ao baixo número de servidores vinculados ao ICMBio, órgão responsável por sua gestão e fiscalização, acaba tendo grande dificuldade em manter a segurança ambiental desse importante fragmento de Mata Atlântica.

De acordo com Delfino (2019) a Rebio Tinguá é considerada de extrema importância biológica para a conservação da biodiversidade, já que é um contínuo florestal que compõe uma das zonas núcleo da Reserva da Biosfera da Mata Atlântica (RBMA), além do Mosaico da Mata Atlântica Central-Fluminense e do Corredor de Biodiversidade da Serra do Mar. Da área total desta unidade de conservação, aproximadamente $97 \%$ do território são ocupados por floresta, sendo que a maior parte está no município de Nova Iguaçu (55,14\%), destacando-se na "Baixada Verde".

33 Muitas destas unidades de conservação fragmentadas no Oeste Metropolitano do Rio de Janeiro, bem como outras áreas de proteção ambiental, sofrem pressão do mercado imobiliário e do próprio poder público para mudarem seu uso do solo, de área vegetada para solo construído, representando um beneficiamento de uma pequena parcela da sociedade. 
34 A Floresta Camboatá é um exemplo. Localizada no bairro de Deodoro, na cidade do Rio de Janeiro, corre o risco de ser derrubada para dar lugar a um autódromo (figura 3), almejando receber a Fórmula 1, numa parceria público privada que envolve a prefeitura.

Figura 3 - Projeto do novo autódromo de Deodoro.

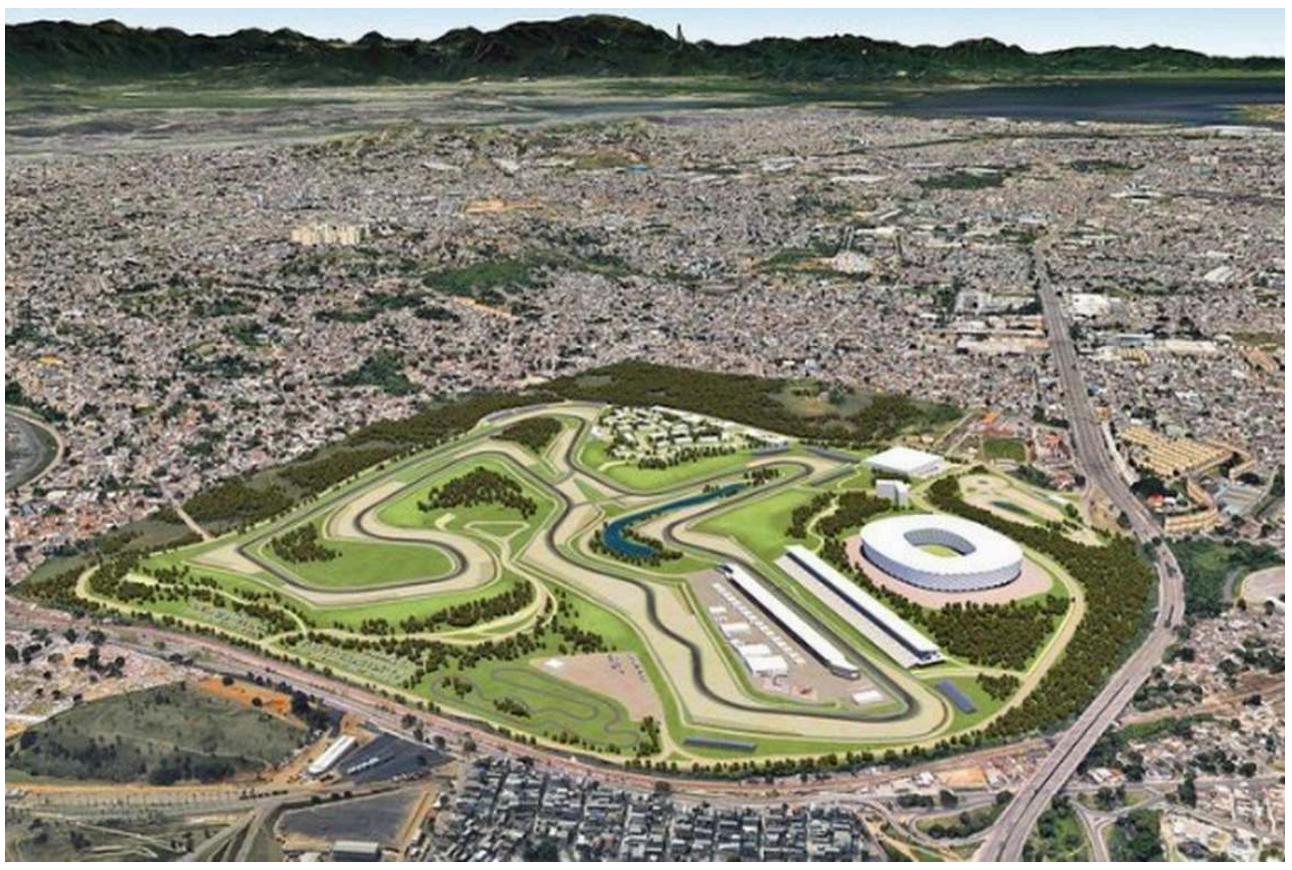

Fonte: Divulgação/Consórcio Rio Motorsports (OECO, 2020).

35 A Floresta do Camboatá é um dos últimos fragmentos de Floresta Ombrófila de Terras Baixas, fitofisionomia da Mata Atlântica intensamente degradada ao longo dos séculos, e que abriga uma rica biodiversidade, além de inúmeras nascentes e brejeiros naturais. Nesta área, como também na Flona Mário Xavier, nos períodos de cheias ressurgem peixes rivulídeos conhecidos popularmente como peixes das nuvens, uma espécie endêmica que corre risco de extinção, diante sua perda de habitat.

Segundo entrevista com Haroldo Cavalcante de Lima, pesquisador do Jardim Botânico do Rio de Janeiro, a cidade perderia muito com a supressão da Floresta do Camboatá, já que é vizinha de bairros como Marechal Hermes, Anchieta e Guadalupe, locais com pouco verde e muito cimento. Desse modo, se houvesse investimento na conservação dessa área, poderiam oferecê-la à comunidade como área de lazer, podendo sediar um centro de pesquisa, visando não só recuperar totalmente a floresta, como também fazêla de sala de aula ao ar livre, oferecendo atividades de educação ambiental, já que a área possui diversas espécies ameaçadas de extinção (OECO, 2020).

É rara a presença de espaços destinados ao lazer no Oeste Metropolitano, e não só de áreas verdes, mas também infraestruturas urbanas, como praças em boas condições para uso dos moradores. Porém, poucos sabem que têm o direito de viver em um ambiente sadio e ecologicamente equilibrado. É nesse contexto que a educação ambiental, assim como a difusão da ciência e de outras informações pelas universidades, se faz necessária, para que a tríade ensino, pesquisa e extensão 
contribua na conscientização e inclusão da sociedade, para que estejam cientes de seus direitos e deveres.

O fortalecimento das políticas de conservação pelo poder público, associado ao planejamento e gestão de áreas prioritárias à conservação, são de suma importância para a manutenção da qualidade ambiental. Desse modo, se faz necessário reconhecer os potenciais ambientais de áreas verdes, bem como seus serviços ecossistêmicos e suas fragilidades, a fim de contribuir para a manutenção da biodiversidade desses espaços, bem como criar oportunidades de desenvolvimento, como exemplo, a proposta da "Baixada Verde".

\section{Os espaços de calor}

39 O clima urbano é aquele produzido pela cidade. A ilha de calor urbana é a principal manifestação do clima urbano, um dos principais problemas ambientais do século XXI (RIZWAN et al., 2008), embora outros fenômenos associados ou resultantes dela façam parte do sistema clima urbano, como a poluição atmosférica e as inundações. A ilha de calor pode representar diferentes espaços de calor, que se distinguem por suas magnitudes térmicas.

40 Considerando o histórico destes estudos para a Região Metropolitana do Rio de Janeiro, Brandão (1996) já destacava a Zona Oeste da cidade do Rio de Janeiro como um espaço favorável para configurar um dos núcleos da ilha de calor urbana diurna em situações de outono e inverno. Os experimentos foram conduzidos por uma rede própria de aparelhos meteorológicos, distribuídos por diversos espaços da cidade do Rio de Janeiro, traçando diferentes trajetos de medições nomeados como "transectos fixos e móveis".

41 Seguindo a linha metodológica de Brandão (1996), Lucena (2005) desenvolveu um estudo para a Zona Oeste e elaborou um mapa de Unidades Topoclimáticas, composta por dados de temperatura, umidade relativa do ar, direção e intensidade do vento, taxas de aquecimento e resfriamento, além de dados de densidade demográfica e construída, tipologia do uso do solo e a cobertura vegetal. As unidades Topoclimáticas da Zona Oeste representam a interação espacial dos atributos do clima, do ambiente construído e do ambiente natural e definem uma classificação (urbana) do clima para a Zona Oeste, sendo esta classificação uma sugestão de operação para a gestão e o planejamento.

42 As Unidades Topoclimáticas foram classificadas em quatro categorias, representadas pelas letras A, B, C e D, sendo as duas últimas as mais críticas (temperaturas mais elevadas, umidade mais baixa e ocupação urbana mais densa) que abrangeu boa parte dos bairros da Baixada de Bangu e Santa Cruz, em oposição à Baixada de Guaratiba, que espacializa a Unidade A, com temperaturas mais baixas, umidade mais elevada e ocupação urbana mais rarefeita.

Dando continuidade aos estudos do campo térmico, Lucena (2012) expandiu o foco da pesquisa para toda a RMRJ, que, segundo o autor, é um espaço favorável à ocorrência da ilha de calor urbana e sujeita às suas reações adversas. Nas palavras do autor,

Pela sua abrangência e representação espacial, sugere-se uma qualificação mais ampla do fenômeno que identifique a sua espacialidade na RMRJ. Neste caso, inova-se com uma terminologia mais adequada, a de Ilha de Calor Metropolitana (ICM), pois cerca 
todos os componentes do espaço metropolitano, discriminados em urbano e periurbano, central, periférico e suburbano, que geram e consolidam a ilha de calor urbana em uma metrópole do porte da RMRJ" (2012, p. 282).

Para este estudo, foram adotados três métodos para avaliar, qualificar e quantificar a ilha de calor no espaço metropolitano, dando mostras da complexidade do fenômeno e da região, assim descritos: a análise de séries temporais que mapeou o campo da temperatura e da pluviosidade no século XX e início do atual, e apontou seus cenários, no tempo e no espaço; o sensoriamento remoto foi aplicado no intuito de mapear o campo da temperatura entre a década de 1980 e 2000, adotando-se, como suporte, os índices de vegetação (NDVI - Índice de Vegetação da Diferença Normalizada) e de área construída (IBI - Índice do Ambiente Construído e ISA - Índice Impermeável de Superfície), revelando os espaços mais quentes da metrópole, determinando e quantificando o núcleo da ilha de calor urbana; a modelagem meteorológica reforçou e comparou o mapeamento da temperatura realizado com o sensoriamento remoto, permitindo adicionar os campos de calor latente e calor sensível, umidade do ar, altura da camada limite e vento para melhor compreender o padrão espacial da temperatura e de configuração da ilha de calor na RMRJ.

Com destaque ao uso do sensoriamento remoto, a ilha de calor urbana teve seu núcleo de $6,1^{\circ} \mathrm{C}$ na década de 2000 e não se materializou numa localidade específica, ou somente na área central de negócios, uma situação recorrente nos países europeus e norte-americanos, que define a ilha de calor clássica. Seu núcleo na RMRJ é, de fato, polinucleado, com vários núcleos de calor distribuídos no espaço metropolitano, destacando-se naquela década os bairros da Zona Oeste da cidade do Rio de Janeiro e as cidades da Baixada Fluminense, muitas delas que fazem parte do Oeste Metropolitano.

47 A inserção de espaços do oeste e noroeste metropolitano no circuito das áreas mais aquecidas é motivo de indagação, pois representa não apenas o subúrbio e a periferia, mas a franja periurbana, que podem ser classificados como uso do solo "rural ou urbano de baixa densidade", categoria ou tipologia muito presente e indefinida nestes espaços do Oeste Metropolitano, que merece aprofundamento sobre a sua resposta para a temperatura da superfície (ou Temperatura da Superfície Continental - TSC - a que é estimada por sensoriamento remoto). Constatam-se que os redutos de elevada concentração de calor são impulsionados por grandes vias, como a avenida Brasil, a BR-116 e o Arco Metropolitano, este em fase de expansão, importantes rotas do Oeste Metropolitano.

Finalmente, no mapa recente da TSC para a RMRJ (figura 4), englobando imagens termais sequenciais entre 1984 e 2019, encontramos o padrão térmico atual do Oeste Metropolitano. No contexto da RMRJ o Oeste Metropolitano abriga as temperaturas mais amenas, o que deve ser considerado benéfico e favorável; contudo, observam-se algumas manchas em tom laranja e vermelho (com temperaturas entre 32 e $38^{\circ} \mathrm{C}$ ) na Zona Oeste, e alguns núcleos nas mesmas tonalidades em cidades da Baixada Fluminense. Esta espacialidade térmica mais elevada acompanha os eixos viários, condutores da expansão urbana e de conexão da região, conforme destacado no parágrafo anterior.

49 Portanto, se considerado todo o espaço da RMRJ, o Oeste Metropolitano ainda é um espaço de amenidade térmica, porém os espaços de calor expandem-se além do núcleo metropolitano e ganham campo no Oeste Metropolitano, alimentando a Ilha de Calor Metropolitana, com núcleos por grande parte da RMRJ. 
Figura 4 - Mapeamento da Temperatura da Superfície Continental (TSC) na RMRJ para o período 1984-2019

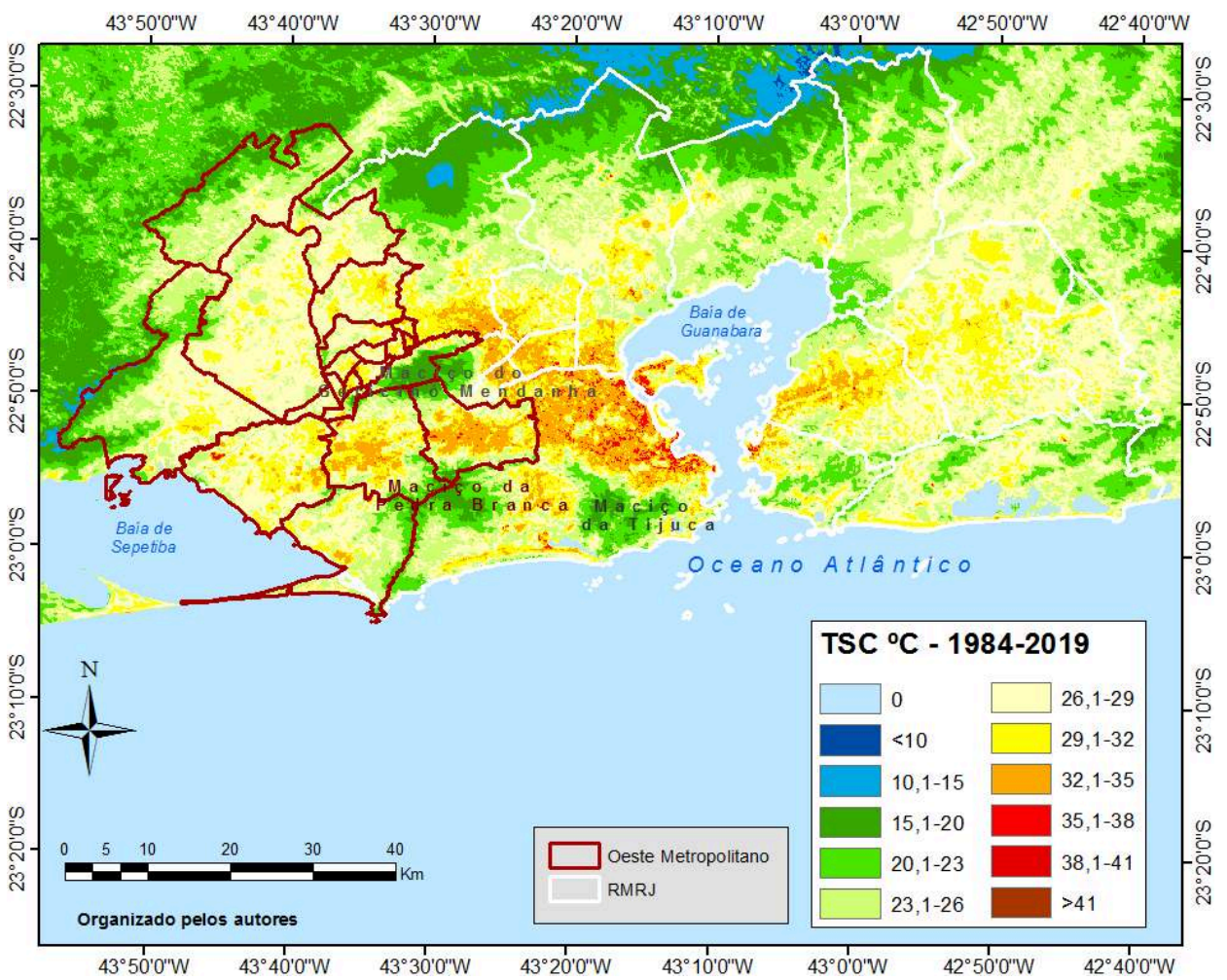

Fonte: LIGA/UFRRJ - Elaborado por Andrews Lucena.

\section{A qualidade do ar}

50 A qualidade do ar na RMRJ não é das melhores, não só por ser a segunda maior concentração de fontes de poluentes do país, mas também devido às características do sítio onde se desenvolveu: uma planície litorânea com três importantes maciços subdivindo-a, e ainda cercada pela Serra do Mar, com 900 metros de altitude em média. Assim, pode-se dizer que a topografia da RMRJ impõe resistência ao escoamento atmosférico, reduz a velocidade do vento e impede que a brisa marítima alcance os bairros e municípios localizados em determinados pontos, contribuindo para a estagnação de poluentes (OLIVEIRA, J., 2004; FARIAS, 2012).

51 Seguindo este princípio, o INEA (2009) criou subáreas, ou bacias aéreas, para diferenciar a produção de poluentes na região metropolitana. Este termo define as áreas formadas em consequência da orientação das vertentes e da altitude do relevo da RMRJ que influenciam na direção dos ventos de superfície e dificultam a dispersão de poluentes.

A RMRJ possui quatro bacias aéreas: Bacia Aérea I que é limitada pela Baía de Sepetiba e Maciço da Pedra Branca, correspondendo ao Oeste Metropolitano, com cerca de 730 $\mathrm{km}^{2}$; a Bacia aérea II que é limitada pelos maciços da Pedra Branca, da Tijuca e o Oceano Atlântico, localizada no município do Rio de Janeiro, envolve as regiões administrativas de Jacarepaguá e Barra da Tijuca, com cerca de $140 \mathrm{~km}^{2}$; a Bacia aérea III, limitada pelos mesmo maciços e Baía de Guanabara, compreendendo a zona norte do município do Rio de Janeiro e grande parte dos municípios da baixada Fluminense, com cerca de $700 \mathrm{~km}^{2}$; 
e a Bacia aérea IV, localizada a leste da baía de Guanabara, correspondendo ao leste metropolitano, que possui $830 \mathrm{~km}^{2}$.

Segundo o Relatório Anual da Qualidade do Ar do Estado do Rio de Janeiro (INEA, 2009), a Bacia Aérea I apresenta as maiores emissões de material particulado na RMRJ, com $58 \%$ do total produzido. Nesta bacia aérea localizam-se distritos industriais e por isso continua recebendo novas unidades industriais com grande potencial poluidor, como é o caso da CSA, uma siderúrgica.

Diante dessa importante interferência do relevo, Farias (2012, 2013) avaliou a capacidade de dispersão e concentração dos poluentes nas diferentes bacias aéreas da RMRJ. Utilizou modelagem atmosférica computacional para simular a liberação de poluentes a partir de fontes fixas localizadas nas quatro bacias aéreas, no verão e no inverno, iniciando em uma condição de tempo predominante até a passagem de uma frente fria para avaliar a sua influência na trajetória das parcelas de ar.

Figura 5 - Localização das estações de qualidade do ar na Bacia Aérea I, Oeste Metropolitano.

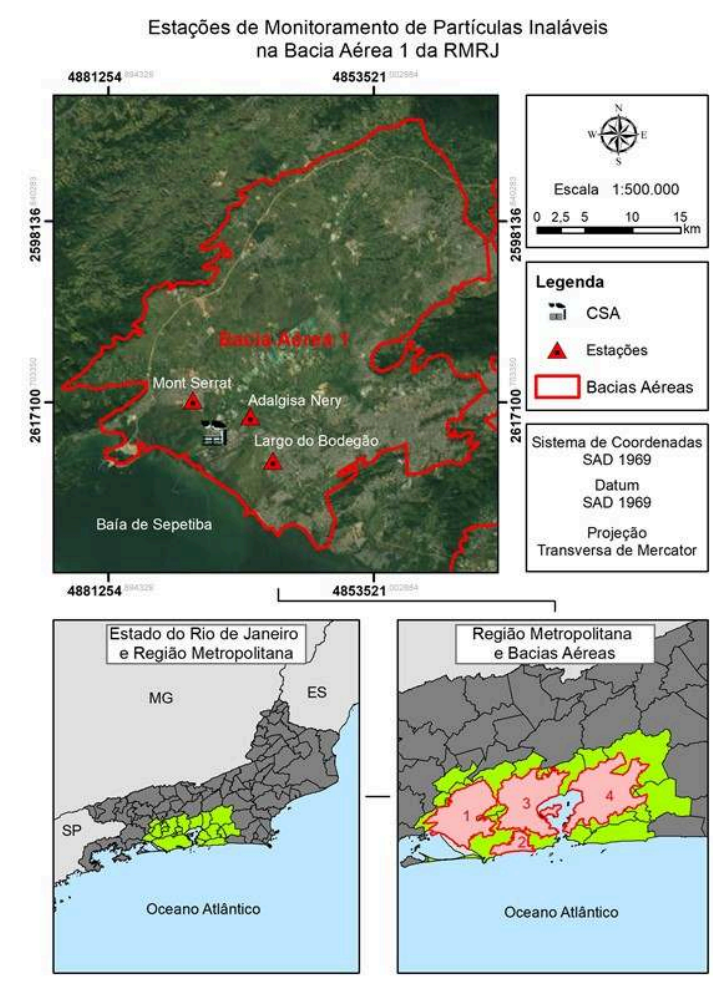

Fonte: LIGA/UFRRJ - Elaborado por Heitor Soares de Farias.

Nas Bacias Aéreas III e IV, os poluentes são carreados em direção à Serra do Mar e forçados a ascender. Ao ultrapassarem essa barreira, os poluentes passam a ser influenciados pelos ventos de grande escala e voltam-se para o mar passando sobre a planície, mas desta vez em grande altitude, o que favorece a dispersão. Nessas bacias aéreas, o relevo, que no início inibe a ação dos ventos, ao ser associado às brisas marinhas, funciona como "rampa de lançamento" para os poluentes, que ascendem por convecção.

Na Bacia Aérea I observou-se maior dificuldade para dispersar os poluentes, devido à presença do Maciço da Pedra Branca, o que deixa esta bacia aérea menos exposta à ação 
dos ventos de leste que sopram paralelos ao litoral do Rio de Janeiro. Outro fator importante é a menor altura da Serra do Mar no limite norte da Bacia Aérea I, canalizando os ventos de grande escala, o que desfavorece o efeito de convecção observado nas demais bacias aéreas da RMRJ.

Assim, conclui-se que a posição e a orientação do relevo têm grande influência na circulação dos ventos e, por conseguinte, na capacidade de dispersão/concentração de poluentes em determinadas áreas da RMRJ. Em todas as simulações, as trajetórias emitidas na Bacia Aérea I alcançaram menor altitude, destacando-se negativamente por apresentar dificuldades para dispersar poluentes, o que mostra que esta área seria a menos indicada para receber unidades industriais, caso fossem consideradas as condições de vento.

Em estudos mais recentes, após conseguir acesso aos dados de qualidade do ar do INEA, Farias (2019) utilizou a série de dados de material particulado (PM10) de três estações localizadas na Bacia Aérea I - duas próximas ao distrito industrial de Santa Cruz, zona oeste do município do Rio de Janeiro, e outra no município vizinho de Itaguaí -, no período de 2009 a 2017. O objetivo foi verificar se o funcionamento da CSA, a partir de 2010, trouxe impacto para a qualidade do ar da região, identificando também as áreas mais afetadas dentro da bacia.

Os resultados mostram que antes da CSA começar suas atividades as estações em Santa Cruz tinham registros mais baixos para PM10, e a qualidade do ar era boa na maior parte do ano. A partir de 2010 até 2016, a estação Largo do Bodegão, em Santa Cruz, a mais próxima à CSA, passou a apresentar os maiores registros em relação às demais estações, com uma redução progressiva do percentual de dias com boa qualidade do ar. Os anos de 2013 e 2015 ficaram marcados pela ocorrência de violações dos padrões de qualidade do ar, 16 e 8 violações, respectivamente, muito acima do permitido pela Resolução Conama no3 (BRASIL, 1990).

Farias (2020) realizou novas simulações computacionais da atmosfera para alguns dias específicos de registro muito elevado de PM10 na estação Largo do Bodegão, em Santa Cruz, para avaliar a origem dos poluentes. Foi possível inferir que a poluição nessas datas não tinha origem na CSA. Por outro lado, apesar de não ter como, com esses dados, apontar a CSA como a responsável direta pela piora na qualidade do ar, indiretamente ela tem uma grande influência nesse quadro.

61 O PM10 é o poluente atmosférico maior responsável por morbidades e mortalidades por doenças respiratórias, e a sua origem está associada aos processos de combustão - desde indústrias, veículos à queima de lixo -, e por isso muito dispersa, o que dificulta a identificação da fonte emissora. Entretanto, pode-se dizer que a chegada da CSA impulsionou tanto o aumento no número de indústrias e veículos pesados, como de população e novas moradias, que também são novas fontes de PM10.

o material particulado é extremamente nocivo à saúde humana, pois segundo a bibliografia médica pode provocar aumento na mortalidade mesmo quando as concentrações médias estão dentro dos padrões internacionais de qualidade do ar (SCHIMMEL \& MURAWSKI, 1976; MAZUMDAR \& SUSSMAN, 1983; CLANCY et al., 2002; DAUMAS et al., 2004), sendo as crianças e os idosos os mais atingidos por doenças respiratórias (SALDIVA et al., 1995; BRAGA et al., 1999; GOUVEIA e FLETCHER, 2000; FREITAS et al., 2004; GOUVEIA et al., 2006). 
63 Hoje, além de unidades industriais com grande potencial poluidor, encontra-se, no Oeste Metropolitano, a CTR-Rio, responsável, como citado parágrafos atrás, por receber todo o lixo produzido na RMRJ, como também a Usina Termelétrica Barbosa Lima Sobrinho, operada pela Petrobrás. Ambos localizam-se especificamente no município de Seropédica, que, como todo o Oeste Metropolitano, constitui-se em áreas menos visíveis da metrópole e, por isso, funcionam como verdadeiros esconderijos espaciais (OLIVEIRA, L., 2014).

64 Os esconderijos espaciais também têm como características o seu conteúdo social, pois são ocupados pelas camadas mais pobres da população, sem articulação política, incapaz de se mobilizar para impedir, ou pelo menos tentar, que empreendimentos com esses perfis se localizem. Isso ajuda a entender o porquê o Oeste Metropolitano continua a receber tais empreendimentos, mesmo sabendo que não tem características geográficas que favoreçam a dispersão dos poluentes, e que, portanto, é a área da metrópole menos indicada para ser ocupada por indústrias. No entanto, o perfil socioeconômico do Oeste Metropolitano se constitui em um agravante na medida em que aumenta a vulnerabilidade social desta população, tornando-a mais suscetível ao adoecimento por doenças respiratórias.

\section{Incêndios florestais}

A problemática dos incêndios florestais também ganha força dentro do Oeste Metropolitano e municípios do entorno. Essa prática é observada através dos diferentes tipos de uso e cobertura do solo ali presentes conjugados ao manejo do fogo produzido em boa parte dos grupos locais que se encontram próximos de Unidades de Conservação.

66 A metodologia aplicada por Sousa et al. (2010) no Parque Estadual da Pedra Branca (PEPB) determinou, através de técnicas de Geoprocessamento, a obtenção de parâmetros para identificação da potencialidade à ocorrência de incêndios com dados considerando a presença do homem e o ambiente como geradores desse fenômeno na paisagem.

O PEPB sofre grande pressão que se amplia ao longo dos anos com o crescimento dos bairros da área de planejamento 5. A vertente norte do Pedra Branca possui cobertura vegetal que possui alta combustibilidade à ignição aos incêndios, resultado propício ao hábito da soltura de balóes e queima de lixo realizados pela população local.

Além disso, estudo realizado por Fernandes et al. (2011), para todo o Estado do Rio de Janeiro, identificou que a susceptibilidade pode se tornar ainda maior de acordo com a época do ano. Esse mapeamento considerou as diferentes respostas da radiação solar extraídas de modelos geomorfológicos e o balanço hídrico visto por dados pluviométricos e de evapotranspiração. O período seco considerado como junho, julho e agosto apresentou grande aumento nas áreas susceptíveis aos incêndios florestais em comparação ao período úmido (dezembro, janeiro e fevereiro) e anual com validação observada por meio de focos de calor divulgados pelo Instituto Nacional de Pesquisas Espaciais (INPE) com percentual de 72,7\% para alta susceptibilidade conforme apontam os autores. 
69 Ao observar os municípios da RMRJ na figura 6, é percebido que existe uma grande concentração de áreas de alta susceptibilidade aos incêndios dentro dos limites do Oeste Metropolitano que demonstram que durante o período seco.

Figura 6 - Mapa de susceptibilidade a ocorrência de incêndios no Estado do Rio de Janeiro durante o período seco com círculo em destaque para o Oeste Metropolitano

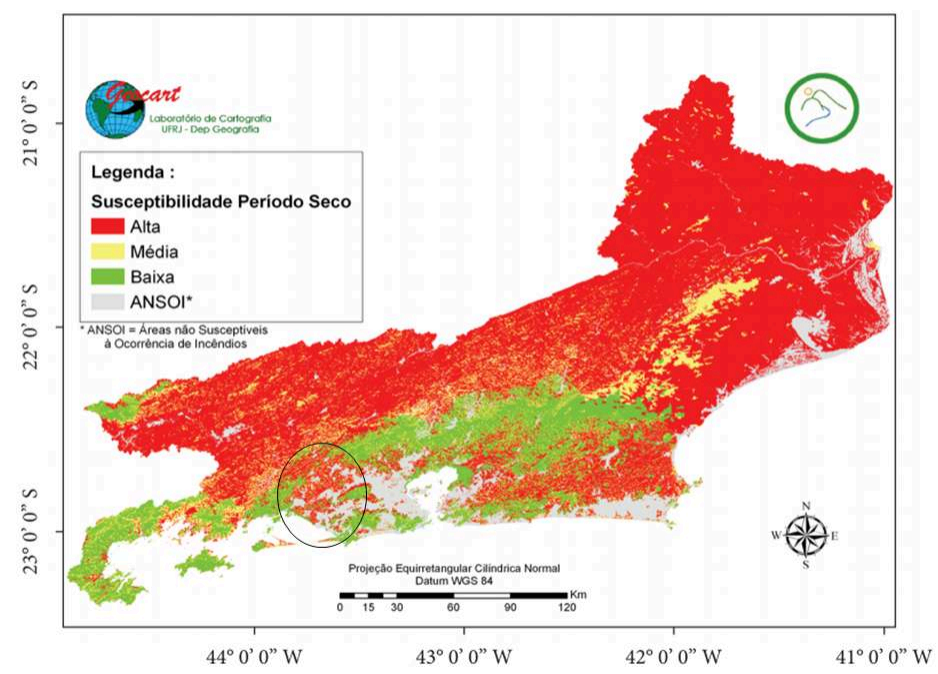

Fonte: Adaptado de Fernandes et al., 2011.

\section{Rede de sensoriamento de baixo custo para monitoramento da qualidade e riscos ambientais}

$\mathrm{O}$ advento de novas tecnologias de informação e comunicação, aliado à popularização de sensores de baixo custo, cria oportunidades para o aumento da geração de dados em tempo real. No passado, a escassez de dados constituía uma das principais barreiras impostas aos gestores públicos no apoio à tomada de decisão.

71 Hoje a situação se inverte, quando o desafio está em gerenciar um "excesso" de dados, totalmente dinâmicos e provenientes de distintas fontes: sensores remotos ambientais, equipes de campo, imagens de satélite.

Componentes eletrônicos que auxiliam o monitoramento e aquisição de dados ambientais, como sirenes de alertas, câmeras, sensores remotos, satélites, hoje podem ser obtidos por custos de aquisição, implantação e operacionalização cada vez mais reduzidos, como é o caso dos componentes Arduino ${ }^{1}$.

73 As estações de monitoramento de dados ambientais compõem uma rede integrada de coleta de dados quantitativos, em tempo real, por meio de sensores de baixo custo, compostos por módulos de aferição de diversos parâmetros ambientais, tais como: precipitação, temperatura do ar, umidade relativa do ar, radiação solar UV, concentração de Monóxido de Carbono, pressão atmosférica, pH, temperatura e turbidez da água, nível da água, dentre outros.

O diagrama apresentado na figura 7 ilustra a estrutura esquemática de operação de uma rede de monitoramento de dados hidrometeorológicos, construída a partir de módulos de sensoriamento ambiental de baixo custo. 
Figura 7 - Representação esquemática da operação de uma rede de monitoramento de dados hidrometeorológicos.
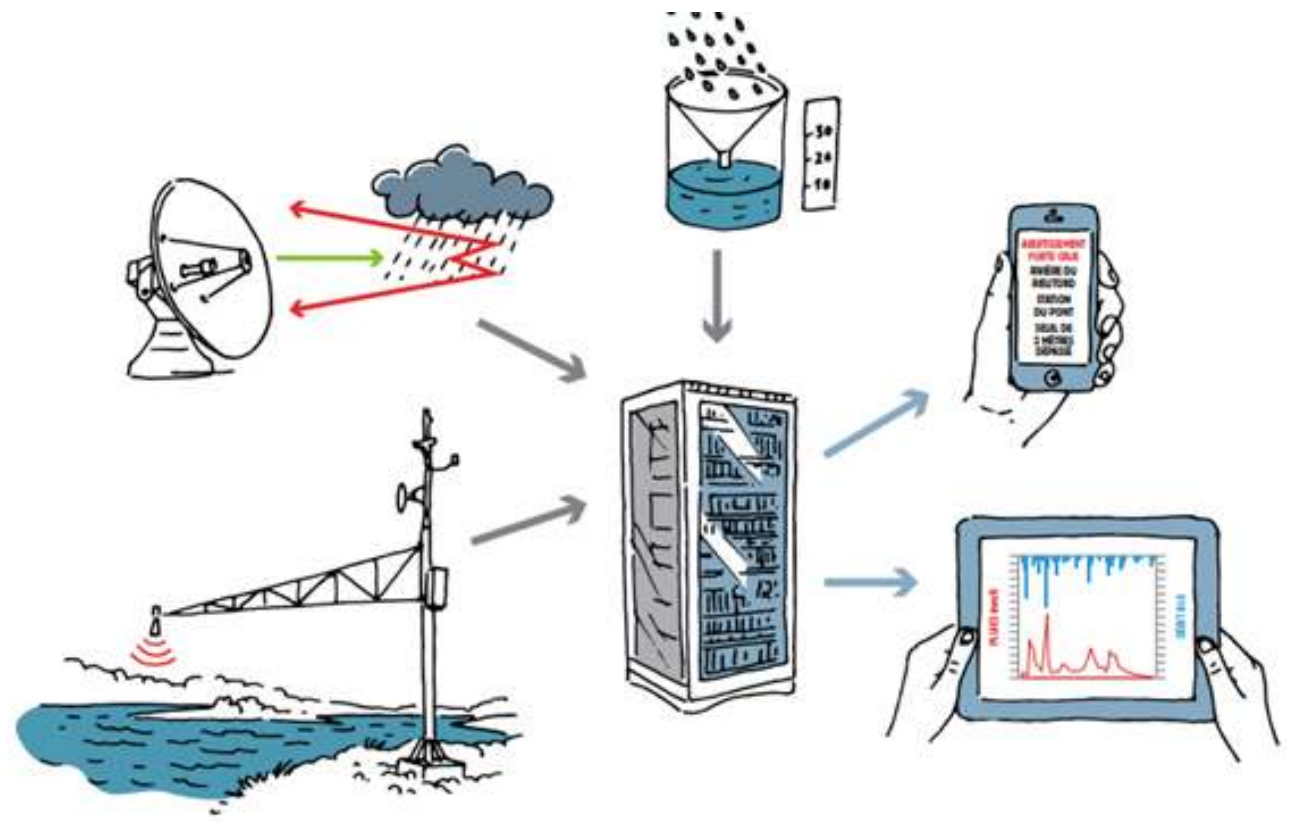

Fonte: LIGA/UFRRJ - Elaborado por Souhayl Ayoubi. e de expansão urbana atual da metrópole e com novas frentes de intervenções espaciais, seja industriais, logísticas ou imobiliárias, de médio a grande porte. Indubitavelmente, o Oeste Metropolitano é um espaço favorável a elevados riscos, seja de cunho social ou ambiental. A ciência geográfica numa proposta aplicada, aliada às geotecnologias, tem papel importante no mapeamento e diagnóstico socioambiental, 
visando conduzir e propor ações agregadoras que atendam as demandas preventivas e mitigadoras do Oeste Metropolitano.

Recomenda-se remodelar o desenvolvimento urbano da RMRJ, com foco no Oeste Metropolitano, através de políticas que assegurem o amortecimento dos impactos e o crescimento nos indicadores sociais e ambientais. É importante que se estabeleça um diálogo entre os pesquisadores, o poder público e a sociedade civil para o equacionamento dos problemas gerados e desafios futuros com tomadas de ação com práticas sustentáveis.

BECK, U. Sociedade de Risco: rumo a uma outra modernidade. São Paulo: Editora 34, 2011 (2a edição). 384 p.

BRAGA, A. L.; CONCEIÇÃO, G. M.; PEREIRA L. A.; KISHI, H. S.; PEREIRA J. C.; ANDRADE, M. F. Air pollution and pediatric respiratory hospital admissions in São Paulo, Brazil. Journal Environmental Medicine; 1:95-102, 1999.

BRANDÃO, A.M.P.M. O Clima Urbano da Cidade do Rio de Janeiro. Tese de Doutorado. Departamento de Geografia, USP/FFLCH, São Paulo, 1996, 362p;

BRASIL. RESOLUÇÃO CONAMA $n^{\circ}$ 3, de 28 de junho de 1990 Publicada no DOU de 22 de agosto de 1990, Seção 1, páginas 15937 a 15939. Legislação.

BUSS, P. M.; PELLEGRINI FILHO, A. A Saúde e seus Determinantes Sociais. PHYSIS: Revista de Saúde Coletiva, Rio de Janeiro, v. 17, n. 1, p. 77-93, 2007.

CEPERJ - Centro Estadual de Estatística, Pesquisa e Formação de Servidores Públicos do Rio de Janeiro. Regiões do Estado do Rio de Janeiro. Disponível em: http:// www.ceperj.rj.gov.br/Conteudo.asp?ident=81. Acessado em 27 jul. 2020.

CLANCY L., GOODMAN P., SINCLAIR H., DOCKERY D. W. Effect of air-pollution control on death rates in Dublin, Ireland: an intervention study. Lancet, 360(9341):1210-4, 2002.

CNDSS - Comissão Nacional sobre Determinantes Sociais da Saúde. As Causas Sociais das Iniqüidades em Saúde no Brasil. Rio de Janeiro: Editora Fiocruz, 2008.

CSA - Estudo de Impacto ambiental da usina siderúrgica CSA. Reference: B6000/05.01. Outubro, 2005.

DAUMAS, R. P.; MENDONÇA, G. A. S. \& LEON, A. P. Poluição do ar e mortalidade em idosos no município do Rio de Janeiro: análise de série temporal. Cadernos de Saúde Pública Rio de Janeiro; 20:311-319, 2004. DELFINO, C. de O. Panorama das Unidades de Conservação e Efetividades dos Conselhos Gestores do Município de Nova Iguaçu-RJ. Monografia de Conclusão de Curso. Curso de Geografia. Universidade Federal Rural do Rio de Janeiro. Seropédica, 2019.

91 FARIAS, H. S. Espaços de risco à saúde humana na região metropolitana do Rio de Janeiro: um estudo das trajetórias de poluentes atmosféricos do Arco Metropolitano, CSA e COMPERJ. Tese de Doutorado. Instituto de Geociências da Universidade Federal Fluminense, Niterói, 2012, $149 \mathrm{p}$.

92 FARIAS, H. S. Bacias aéreas: uma proposta metodológica para o estudo da qualidade do ar em áreas influenciadas pelo relevo. Revista Brasileira de Climatologia. Ano 9 - Vol. 12, pp 48-60, 2013.

FARIAS, H. S. Indicadores Sintéticos de Qualidade de Vida Aplicados na Região Metropolitana do Rio De Janeiro: Uma Análise dos Últimos Censos Demográficos 2000/2010. Revista Continentes (UFRRJ), ano 4, n.6, 2015. 
FARIAS, H. S. O impacto da atividade da CSA na qualidade do ar na Bacia Aérea 1 da região metropolitana da Rio de Janeiro. Revista Brasileira de Climatologia, Ano 15, Vol. 24, pp. 266-279, 2019.

FARIAS, H. S. Espaços de risco à saúde humana sob ameaça da poluição atmosférica: questões fundamentais ao planejamento ambiental na região metropolitana do Rio de Janeiro. ROCHA, A. S. (Org.) Baixada Fluminense: estudos contemporâneos e (re)descobertas históricogeográficas. Duque de Caxias: ASAMIH. 2020, 315p.

FERNANDES, M. C.; COURA, P. H. F.; SOUSA, G. M.; AVELAR, A. S. Avaliação geoecológica da susceptibilidade à ocorrência de incêndios no Estado do Rio de Janeiro. FLORAM, v. 18, n3, p. 299-309, 2011. Disponível em https://floram.org/article/10.4322/floram. 2011.050/pdf/floram-18-3-299.pdf

FREITAS, C.; BREMNER, S. A.; GOUVEIA, N.; PEREIRA, L. A. A. \& SALDIVA, P. H. N. Internações e óbitos e sua relação com a poluição atmosférica em São Paulo, 1993 a 1997. Revista de Saúde Pública:USP; 38(6):751-7, 2004.

FREITAS, J. M. de. Externalidade na disposição final de resíduos sólidos municipais: avaliação para o Centro de Tratamento de Resíduos Sólidos Santa Rosa na região metropolitana do Rio de Janeiro. 2013. 155 f. Dissertação (Mestrado em Saúde Pública e Meio Ambiente) - Escola Nacional de Saúde Pública Sergio Arouca, Fundação Oswaldo Cruz, Rio de Janeiro, 2013.

GOUVEIA, N. ; FLETCHER, T. Time series analysis of air pollution and mortality: effects by cause, age and socioeconomic status. J Epidemiol Community Health; 54:750-5, 2000.

GOUVEIA, N.; FREITAS, C. U.; MARTINS, L. C.; MARCILIO, I. O. Hospitalizações por causas respiratórias e cardiovasculares associadas à contaminação atmosférica no Município de São Paulo, Brasil. Cad. Saúde Pública, Rio de Janeiro, 22(12):2669-2677, 2006.

GUSMÃO, P. P. Vulnerabilidade das Megacidades Brasileiras às Mudanças Climáticas: Região Metropolitana do Rio de Janeiro. In: Nobre, C. and Hogan, D.J., Eds., Projeto Megacidades, Vulnerabilidade e Mudanças Climáticas. INPE/UNICAMP/UFRJ, 2010, 32 p.

INEA - Instituto Estadual do Ambiente. Relatório Anual de Qualidade do Ar. 108p. 2009.

LUCENA, A.J. A Ilha de Calor na Região Metropolitana do Rio de Janeiro. Tese de Doutorado. Instituto Alberto Luiz Coimbra de Pós Graduação e Pesquisa de Engenharia. Programa de Engenharia Civil. Universidade Federal do Rio de Janeiro. Rio de Janeiro, 2012, 328p.

LUCENA, A. J. O campo térmico na Zona Oeste do Rio de Janeiro/RJ: uma contribuição ao estudo do clima urbano. Instituto de Geociências, Departamento de Geografia, Universidade do Estado do Rio de Janeiro. Rio de Janeiro, 2005, 154p;

MARAFON, G. J.; RIBEIRO, M. A.; CÔRREA, R. S.; VASCONSELOS, V. N.. Geografia do estado do Rio de Janeiro: da compreensão do passado aos desafios do presente. Rio de Janeiro, Grama Editora, 2011, 161p.

MATHIAS, M. Racismo Ambiental. EPSJV/Fiocruz, 2017. Disponivel em: < http:// www.epsjv.fiocruz.br/noticias/dicionario-jornalistico/racismo-ambiental> Acessado em: 28/07/2020.

MAZUMDAR, S. ; SUSSMAN, N. Relationships of air pollution to health: Results from the Pittsburgh Study. Archives of Environmental Health; 38: 17-24, 1983.

NOVEMBER, V. Les Territoires du risque: le risque comme objet de refléxion géographique. Berna: Lang. 2002, 220 p. 
OECO. No meio do caminho de um autódromo, há uma floresta. Disponível em: <https:// www.oeco.org.br/reportagens/no-meio-do-caminho-de-um-autodromo-ha-umafloresta/> Acesso em: 29/07/2020. OLIVEIRA, Floriano Godinho de; e OLIVEIRA, Leandro Dias de. Espaço metropolitano, regionalização da economia e reestruturação produtiva no estado do Rio de Janeiro, Brasil. In: Cuyonomics. Investigaciones En Economía Regional, 3(5), 39-65, 2020. Disponível em: http://revistas.uncu.edu.ar/ojs/index.php/cuyonomics/article/view/ 3601. Acesso em 28 de julho de 2020.

111 OLIVEIRA, J. L. F. Análise espacial e modelagem atmosférica: contribuições ao gerenciamento da qualidade do ar da bacia aérea III da região metropolitana do Rio de Janeiro. Tese de Doutorado - COPPE - Universidade Federal do Rio de Janeiro, Rio de Janeiro. 144p, 2004.

OLIVEIRA, L. D. Geografia Econômica e Reestruturação Espacial Contemporânea: Passado e Presente, Desenvolvimento e Utopística. Espaço e Economia [Online], 4 | 2014. Disponivel em: < http://journals.openedition.org/espacoeconomia/855> Acessado em: 26/06/2020;

113 RIZWAN, A. M., DENNIS, Y.C., LEUNG, L. C., et al., 2008, "A review on the generation, determination and mitigation of Urban Heat Island", Journal of Environmental Sciences, vol. 20 pp. 120-128;

114 RELATÓRIO DE IMPACTO AMBIENTAL (RIMA) - CTR Santa Rosa. 22.12.2008. Disponivel em: $\quad$ http://arquivos.proderj.rj.gov.br/inea_imagens/downloads/rima/ RIMA_CTR_SantaRosa.pdf > Acessado em: 28/07/2020.

115 SALDIVA, P. H.; POPE, C. A.; SCHWARTZ, J.; DOCKERY, D. W.; LICHTENFELS, A. J. \& SALGE, J. Air pollution and mortality in elderly people: a time-series study in Sao Paulo, Brazil. Arch Environ Health; 50:159-63, 1995.

SANTOS, A. M. S. P. Economia, espaço e sociedade no Rio de Janeiro. Rio de Janeiro. Editora FGV. 228p, 2003.

SCHIMMEL, H.; MURAWSKI, T. J. The relation of air pollution to mortality. Journal of Occupation Medicine, 18: 316-333, 1976. SECRETARIA DE TURISMO DO ESTADO DO RIO DE JANEIRO. Plano Estratégico do Turismo da Baixada Verde é concluído. Rio de Janeiro. 22.02.2018. Disponível em: < http:// www.turisrio.rj.gov.br/detalhe_noticia.asp?ident=>. Acessado em: 23 jul. 2020.

SOUSA, G. M.; COURA, P. H. F.; FERNANDES, M. C. Cartografia geoecológica da potencialidade à ocorrência de incêndios: Uma proposta metodológica. Revista Brasileira de Cartografia, v. 62, 11, pp. 277-289, 2010. Disponível em http://www.seer.ufu.br/ index.php/revistabrasileiracartografia/article/view/43708

120 VARGAS, K. B.; FARIAS, H.; SAMPAIO, A, C.; BARROS, R. C.; SOUZA, R. L. N. de. A Floresta Nacional Mário Xavier Como Espaço Livre de Uso Público no Município de Seropédica-RJ. Gestão, percepção e uso de espaços públicos. Capítulo 7. Editora Anap. Tupã, 2019, pág. 115. Disponível em: <https://www.amigosdanatureza.org.br/biblioteca/livros/item/cod/ 186> Acessado em 23/07/2019.

VEYRET, Y. ; RICHEMOND, N. M. (org.) Os riscos: o homem como agressor e vítima do meio ambiente. São Paulo: Contexto, 2007. 


\section{NOTAS}

1. Arduíno - https://www.arduino.cc/.

\section{RESUMOS}

O Oeste Metropolitano do Rio de Janeiro compreende os bairros da Zona Oeste, ou Área de planejamento 5, da cidade do Rio de Janeiro e os municípios de Nova Iguaçu, Japeri, Queimados, Seropédica, Paracambi e Itaguaí, pertencentes à Baixada Fluminense. A região é responsável pelo abastecimento de água de grande parte da Região Metropolitana do Rio de Janeiro, sendo, portanto, uma região enquadrada pelo Ministério do Meio Ambiente como prioritária para a conservação e implementação de políticas públicas socioambientais. O Oeste Metropolitano tornou-se bastante visado nos últimos anos, especialmente pela sua posição geográfica, localizado no mais importante eixo geoeconômico do país (RJ - SP - Belo Horizonte), além de grande riqueza natural, atribuída aos recursos naturais e serviços ecossistêmicos oferecidos em superfície e subsuperfície. Mesmo diante do seu potencial ambiental, a região é marcada por uma série de impactos ambientais, decorrentes principalmente pela falta de saneamento básico adequado, irregularidades no descarte de rejeitos e despejo de efluentes industriais in natura e atividades de mineração, como extração de areia e de pedras. Com o intuito de descrever as características socioambientais do Oeste Metropolitano, objeto de estudo do Laboratório Integrado de Geografia Física Aplicada (LIGA/UFRRJ), o presente artigo objetiva-se apresentar um panorama geográfico dessa região, visando diagnosticar os riscos iminentes e os índices de vulnerabilidade socioambientais, bem como, apresentar estratégias preventivas aos riscos potenciais do uso e ocupação territorial, oferecendo subsídios para a produção do ordenamento territorial e para um planejamento urbano sustentável.

The West Metropolitan region of Rio de Janeiro state comprises the districts of Rio de Janeiro city west zone and the municipalities of Nova Iguaçu, Japeri, Queimados, Seropédica, Paracambi and Itaguaí. The region is responsible for the water supply of a large part of Rio de Janeiro Metropolitan area, and is therefore a region classified by the Ministry of the Environment as a priority for the conservation and implementation of public socio-environmental policies. The West Metropolitan has become quite popular in recent years, especially for its geographical position, located on the country's most important geoeconomic axis (Rio de Janeiro - São Paulo Belo Horizonte), in addition to the great natural wealth attributed to natural resources and ecosystem services offered in its surface and subsurface. Even from an environmental potential perspective, the region is marked by a series of environmental impacts, mainly due to the lack of adequate basic sanitation, precarious sewage network, and massive irregular discharge of industrial effluents and mining activities, such as sand and stone extraction. Thus, in this study, the Integrated Laboratory of Applied Physical Geography (LIGA/UFRRJ) describes the socioenvironmental characteristics of Rio de Janeiro West Metropolitan region. Moreover, the work also presents a geographical panorama of this region, in order to diagnose the imminent risks and the indices of socioenvironmental vulnerability, as well as presenting preventive 
strategies to the potential risks of territorial use and occupation, offering subsidies for the production of territorial planning and for sustainable urban planning.

El Oeste Metropolitano de Río de Janeiro comprende los distritos de la Zona Oeste, o Área de Planificación 5, de la ciudad de Río de Janeiro y los municipios de Nova Iguaçu, Japeri, Queimados, Seropédica, Paracambi e Itaguaí, perteneciente a la Baixada Fluminense. La región es responsable del abastecimiento de agua de gran parte de la Región Metropolitana de Río de Janeiro, por lo tanto, es una región clasificada por el Ministerio del Medio Ambiente como una prioridad para la conservación e implementación de políticas públicas sociales y ambientales. El Oeste Metropolitano se ha vuelto bastante popular en los últimos años, especialmente debido a su posición geográfica, situado en el eje geoeconómico más importante del país (RJ - SP - Belo Horizonte), además de la gran riqueza natural, atribuida a los recursos naturales y servicios ecosistémicos ofrecidos en la superficie y el subsuelo. Incluso en vista de su potencial ambiental, la región está marcada por una serie de impactos ambientales, principalmente debido a la falta de saneamiento básico adecuado, irregularidades en la disposición de relaves y descarga de efluentes industriales frescos y actividades mineras, como la extracción de arena y piedra. Para describir las características socioambientales del Oeste Metropolitano, objeto de estudio del Laboratorio Integrado de Geografía Física Aplicada (LIGA/UFRRJ), este artículo tiene como objetivo presentar un panorama geográfico de esta región, con el fin de diagnosticar los riesgos inminentes y los índices de vulnerabilidad socioambiental, así como, presentar estrategias preventivas a los riesgos potenciales del uso y ocupación territorial, ofreciendo subsidios para la producción del ordenamiento territorial y para una planificación urbana sostenible.

L'Ouest Métropolitain du Rio de Janeiro comprend les quartiers de la Zone Ouest, ou Zone de Planification 5, de la ville de Rio de Janeiro, et les municipalités de Nova Iguaçu, Japeri, Queimados, Seropédica, Paracambi et Itaguaí, appartenant à la Baixada Fluminense. La région est responsable pour l'approvisionnement en eau d'une grande partie de la Région Métropolitaine de Rio de Janeiro, étant donc une région classée par le Ministère de l'Environnement comme une priorité pour la conservation et la mise en œuvre des politiques socio-environnementales publiques. L'Ouest Métropolitain est devenu assez ciblé ces dernières années, notamment pour sa position géographique, située sur l'axe géoéconomique le plus important du pays (RJ - SP - Belo Horizonte), en plus de la grande richesse naturelle attribuée aux ressources naturelles et aux services écosystémiques offerts en surface et sous-surface. Même au regard de son potentiel environnemental, la région est marquée par une série d'impacts environnementaux, principalement dus au manque d'un adéquat assainissement de base, aux irrégularités dans l'élimination des résidus et au rejet d'effluents industriels in natura et aux activités minières, telles que l'extraction de pierres et de sable. Afin de décrire les caractéristiques socioenvironnementales de l'Ouest Métropolitain, objet d'étude par le Laboratoire Intégré de Géographie Physique Appliquée (LIGA / UFRRJ), cet article vise à présenter un panorama géographique de cette région, afin de diagnostiquer les risques imminents et les indices de la vulnérabilité socio-environnementale, ainsi que la présentation de stratégies préventives aux risques potentiels de l'utilisation et de l'occupation territoriale, en offrant des subventions pour la production d'aménagement du territoire et pour un urbanisme durable. 


\section{ÍNDICE}

Mots-clés: Baixada Fluminense, Ouest Métropolitain de Rio de Janeiro, qualité environnementale, vulnérabilité, risques socio-environnementaux.

Palavras-chave: Baixada Fluminense, Oeste Metropolitano do Rio de Janeiro, Qualidade Ambiental, Vulnerabilidade, Riscos Socioambientais.

Palabras claves: Baixada Fluminense, Metropolitano Oeste de Río de Janeiro, Calidad Ambiental, Vulnerabilidad, Riesgos Sociales y Ambientales.

Keywords: Baixada Fluminense, West Metropolitan region of Rio de Janeiro State, Environmental Quality, Vulnerability, Social and Environmental Risks.

\section{AUTORES}

\section{HEITOR SOARES DE FARIAS}

Geógrafo com experiência em Planejamento Ambiental-Urbano. Membro do Laboratório Integrado de Geografia Física Aplicada (LiGA). Professor do Departamento de Geografia/IA e do Programa de Pós-Graduação em Geografia (PPGGEO) da Universidade Federal Rural do Rio de Janeiro (UFRRJ). E-mail: heisofa@gmail.com.

\section{KARINE BUENO VARGAS}

Geógrafa com experiência em Biogeografia, Geomorfologia e Educação Ambiental. Coordenadora do Programa de Extensão Guarda Compartilhada Flona Mário Xávier. Membra do Laboratório Integrado de Geografia Física Aplicada (LiGA). Professora do Departamento de Geografia/IA e do Programa de Pós-Graduação em Geografia (PPGGEO) da Universidade Federal Rural do Rio de Janeiro (UFRRJ). E-mail: karinevargas@gmail.com.

\section{TIAGO BADRE MARINO}

Bacharel em Ciência da Computação, com experiência em desenvolvimento de Sistemas de Informações Geográficos e Geoprocessamento. Membro do Laboratório Integrado de Geografia Física Aplicada (LiGA). Professor do Departamento de Geografia/IA e do Programa de PósGraduação em Geografia (PPGGEO) da Universidade Federal Rural do Rio de Janeiro (UFRRJ). Email: tiagomarino@ufrrj.br.

\section{GUSTAVO MOTA DE SOUSA}

Geógrafo com experiência em Cartografia Temática, Sensoriamento Remoto e Modelagem Ambiental. Membro do Laboratório Integrado de Geografia Física Aplicada (LiGA). Professor do Departamento de Geografia/IA e do Programa de Pós-Graduação em Geografia (PPGGEO) da Universidade Federal Rural do Rio de Janeiro (UFRRJ).E-mail: gustavoms@ufrrj.br.

\section{ANDREWS JOSÉ DE LUCENA}

Bacharel e Mestre em Geografia. Doutor em Ciências atmosféricas. Membro do Liga e professor do Ppggeo/Ufrrj. E-mail: lucenageo@yahoo.com.br. 